\title{
Gesundheitsatteste
}

\section{Tauchsportler von Kopf bis Fuß untersuchen!}

\section{Hier steht eine Anzeige.}

\section{In Ausgabe 12/2015 ging es in den "Geschichten aus der Praxis" auf S. 10 um die sogenannten Gesundheitsatteste. Eine Leserin schrieb, dass sie diese möglichst unkom- pliziert ausstellt und drei symbolische Euro kassiert. Ein anderer Leser hält das für einen gefährlichen Weg:}

—Es trifft zu, dass diese pauschalen Attestwünsche zunehmen und wir selbst mit umfangreicher und damit teurer Untersuchung keine sichere Aussage machen können - schon gar nicht über möglicherweise in der Zeit danach auftretende Erkrankungen und Komplikationen. Dies wird von uns auch nicht erwartet. Der TÜV-Sachverständige bescheinigt auch nur, dass ein Fahrzeug zum Zeitpunkt der Untersuchung verkehrstauglich ist.

Ich führe seit über 30 Jahren Untersuchungen gemäß G 26 für Atemschutzträger durch. Auch hier kann ich nur attestieren, dass entsprechend der Vorgaben zum Zeitpunkt der Untersuchung Tauglichkeit bestand.

Die Sportvereine, Tauchclubs, Restaurantbesitzer etc. wollen sich juristisch absichern. Im Streitfall können sie darauf verweisen, dass ein ärztliches Attest die Tauglichkeit bescheinigt hat. Und so werden tagtäglich in den Praxen Gefälligkeitsatteste ausgestellt. Man will ja seinem Patienten helfen. Doch was nützt ein 3-Euro-Attest vor Gericht? Der Sachverständige wird es genussvoll zerpflücken. Und die Versicherung des Arztes wird sagen, er habe grob fahrlässig gehandelt und nicht bezahlen.

Ich habe manchen Patienten verloren, weil ich nur bescheinige, was ich untersucht habe, und den gesamten Umfang nach GOÄ (einfacher Satz) abrechne. So muss ein Tauchsportler eben nicht nur von Kopf bis Fuß untersucht werden, sondern benötigt auch Ergometrie, Lungenfunktion und einen einfachen Hörund Sehtest. Und das geht nicht für drei Euro! Der Patient gibt doch auch sonst Geld für sein Hobby aus.

Es wäre schön, wenn unsere Kammern und deren Juristen hier Vorgaben liefern würden. Wir bezahlen diese ja durch unseren Zwangsbeitrag. Solange keine klaren Vorgaben wie etwa bei der Berufsgenossenschaft da sind, empfehle ich eine umfangreiche Dokumentation, eine ausreichende Untersuchung und eine Angabe im Attest, was untersucht wurde.

- Dr. med. Peter Karl Eugen Göhring, Schillerstr. 9, D-75382 Althengstett

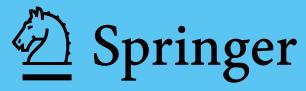

